Volume: 11 Issue: 1 Year: 2014

\title{
Social change and adolescent rites of passage: A cross cultural perspective
}

\author{
Franklin N. Glozah, ${ }^{1,2}$ \\ Suleman Lawani ${ }^{3}$
}

\begin{abstract}
This paper examines the role social change and modernity plays in adolescent rites of passage in developing and developed countries. The 'Dipo' rite of the Krobo in Ghana is compared and contrasted with the 'Russ' in Norway with specific reference to social change and modernity. A salient distinction in both rites of passage is the observance of a set of processes, procedures and stages adolescent undergo including, inter alia, participation in a procession characterized by a special symbolic outfit to annunciate the celebration of the rite. Adolescents in both cultures believe they are parting the adolescent stage of life and preparing to assume young adult roles. Whiles adults participate or supervise the Dipo, the Russ has nothing to do with adult supervision or participation. If an adolescent fails to participate in the Dipo she is not recognised by her family and not fit for marriage but adolescents are not subjected to this treatment should they decide not to participate in the Russ. In general both rites have undergone several positive and/or negative transformations and modifications due to social changes and modernity. This paper, thus, argues that as a result of social change and modernity adolescents have developed rites of passage in which explicit individualism is projected as a value.
\end{abstract}

Keywords: Rites of passage, Social change; Modernity; Culture; Dipo; Russ; Ghana; Norway

\section{Introduction}

Adolescence represents an important stage of physical, social, psychological, and cognitive growth (Brindis \& Ott, 2002). As they are neither children nor adults, adolescents experience varied social and psychological events in life that influences how they transit into adulthood. There has been a pronounced emphasis on how social context variables influence adolescent development into adulthood as the transition from adolescence to adulthood is very critical, where much hangs in the balance (Kloep, Güney, Çokb, \& Simsek, 2009). As childhood became more recognized as a

\footnotetext{
${ }^{1}$ Ph.D., Senior Lecturer, Department of Psychology and Human Development, Regent University College of Science and Technology, Ghana, franklin.glozah@regentghana.net

2 Department of Psychology, Norwegian University of Science and Technology, Norway

${ }^{3}$ MPhil, Lecturer, Centre for Studies in African Development, Regent University College of Science and Technology, Ghana, suleman.lawani@regentghana.net
} 
Glozah, F. N., \& Lawani, S. (2014). Social change and adolescent rites of passage: A cross cultural perspective. International Journal of Human Sciences, 11(1), 1188-1197. doi: 10.14687/ijhs.v11i1.2909

distinct stage of development, adolescence subsequently emerged as a unique and separate developmental stage in the life span (Scheer, Gavazzi, \& Blumenkrantz, 2007). Adolescence has been described as a stage of breaking away from one's childhood to prepare for adulthood, a period during which there are ever-present conflicting themes that the adolescent confronts (e.g. responsibility/irresponsibility, child-like ambitions/adult-like ambitions) in their social world (Hendry \& Kloep, 2012; Hendry \& Kloep, 2012; Hall, 1904).

According to Van Gennep (1960) rites of passage are momentous social events that help guide and affirm a transition from one status in life to another. According to Bossard and Boll (1988) it is a period of training and selection, and its goal is conservation of the best interests and values of the culture in which they find themselves. Rites of passage are construed to be ceremonies that relate and convey dramatization to major life events, such as, birth, coming-of-age initiations, marriage, and death, and they consist of a series of rituals that convey individuals from one social status or role to another (Markstrom \& Iborra, 2003). Van Gennep (1960) coined the phrase rites de passage and delineated its basic structure as one that involved well-defined elements of separation, transition, and incorporation. Accordingly to Van Gennep (1960), although rites of passage are all very different, each one shares the three stage process:

The separation stage has been described as a temporal removal from society, where an individual or a group of individuals lose their identity. The separation stage of a rite of passage is usually abrupt or violent in nature, ruptures ties to self, family, community and so on. It often involves alienation or movement across boundaries whereby the individual is geographically relocated temporarily (Jacquelynne, Templeton, Barber, \& Stone, 2003). At the transition stage the individual learns the roles and expected behaviours of the new stage he/she is entering. The second stage in a rite of passage, the "in-between" time in which the participant has lost his/her old identity, but has not yet been fully re-incorporated into the community with a new identity (Turner, 1969). Finally, at the incorporation stage the individual is re-admitted back into society as a different person. This usually involves moving the participants out of isolation and back into the community with a new identity. This suggests that the individual would have returned as a transformed person as they have acquired new skills, information and new ways of thinking and doing things, as a result of performing a set of rituals. Completion of the incorporation stage is characterized by the individual successfully progressing into a new status and is once again in a stable state (Markstrom \& Iborra, 2003).Acording to Scheer, Gavazzi, and Blumenkrantz (2007) each of these events is linked deeply to intrapsychic processes, and requires individual and community attention in order for the person 
Glozah, F. N., \& Lawani, S. (2014). Social change and adolescent rites of passage: A cross cultural perspective. International Journal of Human Sciences, 11(1), 1188-1197. doi: 10.14687/ijhs.v11i1.2909

to make a successful transition in concert with the community retaining its balance in the face of the individual's change of status.

For that matter, this progress from one phase of life to another is expected to be smooth and successful with the development of positive adult roles and attributes. However, modernity and social changes have had an immense impact on the transition process and the outcome thereafter. Contemporary social changes have distorted and altered the transition processes thereby having either a positive and/or negative influence on the outcome phase of life - adulthood. Hess and Copeland (1997) maintain that as adolescents progress toward adulthood their reliance on family continues to decrease and the influence of peers becomes increasingly important. The generation gap and problem behaviours considered a normal part of adolescence, are in fact culturally produced (Isaksonl \& Jarvis, 1999).

Nonetheless, rites of passage are important for adolescents in all societies because without it adolescents attempt to create rites of passage for themselves by engaging in risk-taking behaviour such as violence, substance use, gangs, bullying, and delinquency (Merten, 2005). The aim of this paper, therefore, is to critically compare and contrast adolescent rites of passage between a developing country - Ghana and a developed country - Norway by specifically examining the dynamic role of modernity and social changes.

\section{Dipo - Ghana}

The 'Dipo' rite is practiced by the Krobo people in the Eastern region of Ghana. The essence of this rite of page is for adolescent girls to maintain their chastity until marriage. It is a practice observed by indigenous natives and meant to usher young girls into society and adulthood (Adjaye, 1999). This is a formal symbolism that a girl has ceased to be a child and now assuming adult roles, especially marriage. She is supposed to be seen as a young adult who will take her place in adult society, assume responsibility for her own behaviour and decisions, and be ready for a career or for marriage. If this rite is not performed for an adolescent girl, she is regarded as unclean and not fit for marriage.

For the separation stage, the Dipo girls are taken from their respective homes and camped on the Krobo mountains. They are usually kept in this secret camp by elderly women who are experienced in this initiation practice. The initiates are not allowed to contact any member of their family during this period. During the transition stage the girls are taught various adult roles and given the necessary skills to be able to function as responsible adults in society. For example, the girls are taught how to cook, sweep, and wash clothes as well as how to behave as married women living 
Glozah, F. N., \& Lawani, S. (2014). Social change and adolescent rites of passage: A cross cultural perspective. International Journal of Human Sciences, 11(1), 1188-1197. doi: 10.14687/ijhs.v11i1.2909

with a man. Other skills that they learn include basket weaving, pottery making and how to always preserve and keep their bodies clean and neat as women. Furthermore, they are taught the proper strategies for the resolution of misunderstandings and quarrels that may arise in the course of marriage.

During the Incorporation stage, the girls are lined up half naked and paraded in a form of a procession through the principal streets of the town to indicate to the society that the girls are virgins and properly groomed for marriage. According to Adjaye (1999) one significant moment on the day of the event is that the girls are richly decorated with beads, jewelry and expensive velvet or wax print loin cloths. From whatever source a mother could obtain these items of decoration, family treasures, purchasing, and borrowing, parents make sure that their daughters are most elegantly adorned. None of the girls would have a reason to lie about their virginity as the streets are full of the residents of the town who could expose any girl they know was not a virgin. In addition, the elderly women who train them at camp have a way of verifying whether a girl was a virgin prior to the rite - through physical examination. Based on experience they agree on some criteria to determine if a particular girl is a virgin or not. Usually more than one adult female does the examination and this is intended to make the practice of physical examination, somehow reliable.

Furthermore, before the girls pass through the final rite, they are made to sit down, then up, and down three times on a 'sacred stone'. It is believed that any girl who is not a virgin will be stuck on the 'sacred stone' on the third count (Adjaye, 1999). This scares girls in the community and so ensures that girls do everything possible to maintain their chastity until marriage. As a punishment for violating this social injunction i.e. losing her virginity prior to the day of the rites, a girl is exiled and not allowed to return home until the necessary cleansing and reintegration rites are performed.

For the first time since the initiation started, some of the girls could now be seen wearing earrings. It is a proud moment not only for the initiates who had endured the rituals but more so for their parents who now manifest the satisfaction that their daughters have joined the ranks of the initiated and have gained the status of full-fledged womanhood as demanded by Krobo tradition. They are therefore reincorporated into the society as adults and every member of the Krobo society welcomes and respects them. The warm welcome and respect is then extended to the families of these girls. This encourages more families to present their daughters the following year for the rites to be performed on them. For the general community, what distinguishes the initiated girls and the 
Glozah, F. N., \& Lawani, S. (2014). Social change and adolescent rites of passage: A cross cultural perspective. International Journal of Human Sciences, 11(1), 1188-1197. doi: 10.14687/ijhs.v11i1.2909

uninitiated are the scars that are put on the girls during the rite. Scars are put on the hands, belly and back of the initiated girls as proof of initiation.

\section{Russ- Norway}

The 'Russ' ("russefeiring") is a traditional celebration for Norwegian high school students in their final spring semester. It is a special rite of passage to adulthood in the form of prolonged graduation parties in which adolescents wear special clothes, celebrate, and drink beer and spirits from the 1st through the 17th of May every year (Beccaria \& Sande, 2003; Corsaro \& Johannesen, 2013). It is seen as a period when adolescents believe they are departing adolescence and preparing to assume adult roles and so they exhibit behaviours that adults are supposed to exhibit such as drinking alcohol and engaging in sexual activity. At the separation stage, as espoused by Van Gennep (1960), adolescent boys and girls start preparing for this celebration by saving their own money. They are not really separated from their parents but begin to do things on their own. Some of them buy minivans or a bus to drive around and party, and they save money for the special outfit and for alcohol, parties and 'russetreff' (russ - meetings).

The transition stage of the Russ involves activities such as drinking as many beers as you can in a short time, pile as many people as possible in a phone booth, as well as many other activities which many describe as bizarre. They run naked through the main street in town, and go to a shop with a person of the same sex to buy a cucumber or banana with Vaseline. Whiles talking about the size of the cucumber/banana, they lie down on the pedestrian crossings (zebra stripes), wash them with a toothbrush during rush hour, and spend the night in the middle of a roundabout. In addition, they walk around in pyjamas and slippers for a day, be tied together with another Russ (either handcuffs on their hands or tied together by the legs). These are all expressions of freedom or 'childish' behaviour which the participants believe they are engaging in for the last time (Corsaro \& Johannesen, 2013).

Again, during the transition period, the Russ participants engage in sexual activity - thought to be an activity for adults. It is understood that many people do not appreciate this aspect of the Russ, apparently because of the chaotic experiences witnessed at this stage. The Russ does not appear to have any reincorporation into society as there was no major separation in the first place (Beccaria \& Sande, 2003). One remarkable feature of the separation stage however, is the special uniform or suits of different colours that they wear to distinguish them from the rest of the Norwegian society. The suites have three basic colours: red, black and blue - each colour represents the programme studied in high school. The clothes mark the period of marginalization with the rest of the society. 
Glozah, F. N., \& Lawani, S. (2014). Social change and adolescent rites of passage: A cross cultural perspective. International Journal of Human Sciences, 11(1), 1188-1197. doi: 10.14687/ijhs.v11i1.2909

Putting on these clothes signifies that the adolescent is permitted to behave in ways that includes both extreme adult activities and playful childish behaviour.

The Russ participants are seen to overemphasize behavioural features exhibited by both adult and children's world to indicate their Russ community, and as a means to progress to their new status young adulthood. From observation, the Russ emerges apparently due to a lack of explicit rites and ritual practices in western cultures. Consequently adolescents create their own rite to represent a transition. Through their creative participation in traditional rituals, adolescents develop and share their own collective identity while also contributing to civic society more generally (Corsaro \& Johannesen, 2013). Adolescents live descent lives afterwards and do not incorporate negative features of the rite into their new young adult status.

An extension of the 'traditional' argument is that social pressures exist which encourage adolescents to participate in the Russ rite of passage. The pressures come from external agents such as parents, relatives, friends, and so on. The adolescent however, does not experience the neglect which Pickering (1974) described as bringing opprobrium or even ostracism. The Norwegian Russ does not observe this feature of neglect should one opt not to participate in the rites although friends and colleagues expect all adolescent to participate.

\section{Social change, modernity and rites of passage}

Due to modernity and social change, societies such as the Krobo are gradually but steadily modifying cultural rites (Adjaye, 1999; Karianjahi, 2008). Also, as more and more people take to Christianity, Islam and other religions, they eschew traditional rites and rituals that are associated with rites of passages. One plausible reason that undermines the Dipo is that fact that it is nearly practically impossible to physically verify a girl's virginity.

Such information and other related ones are always on both the print and electronic media. Adolescents become aware of this news and it compels them to believe that they can lose their virginity and still go through the Dipo rite without being detected. Besides, they do not believe they will be stuck on the 'so called' sacred stone in case they lose their virginity prior to the initiation rite. This has somehow resulted in the inability of the Dipo rite to achieve its true purpose of breeding girls to abstain from sex and become responsible women in society. There are similar rites across different cultures in Ghana that are meant to minimize or eliminate chaos during adolescence but which has been adulterated. This has also made people lose interest in, if not rejected, the celebration of rites of passage entirely. 
Glozah, F. N., \& Lawani, S. (2014). Social change and adolescent rites of passage: A cross cultural perspective. International Journal of Human Sciences, 11(1), 1188-1197. doi: 10.14687/ijhs.v11i1.2909

Indeed the earliest changes to the Dipo were occasioned by the activities of Christian missionaries who sought to modernize the Krobo society. This led to a reduction in the time spent at the secret camp from about one year to about two weeks. Also, scarification and other aspects of the rite became unattractive. The media and other sources of information have made the girls not to take seriously many of the rituals performed on them, especially with keeping their virginity (Karianjahi, 2008). Social change processes could also account for the disappearance or lack of traditional rites in Norway thereby leading to the development of a spontaneous rite in the form of the Russ. It may be that adolescents here have invented their own modus of transitional rite. This might explain why adults or the elderly do not participate or supervise the rite compelling one to believe that, after all, there may be nothing like a rite of passage but merely a period of partying and merry making for adolescents.

Pickering (1974) asserts that in less developed societies there is a higher level of ritualization than in industrial societies, and the use of visual and physical symbols, which epitomize social reality, is more pronounced. The Russ rite in Norwegian culture might not be a rite as such, but a period where adolescents perceive themselves as transiting adolescence and getting ready to assume adult roles in society by organizing parties and making merry (Corsaro \& Johannesen, 2013). Unlike the Dipo, the Russ participants do not have adults or the elderly preparing them for the transition, they rather prepare themselves for the new status of adulthood.

The Dipo, was meant to help prevent teenage pregnancy, truancy and drug use and abuse among adolescents. The problem of drug use, teenage pregnancy, and disobedience appear to have been well curbed by the Dipo rite. One of the aims of the Dipo rite is to socially, develop adolescent girls to fit well into society by becoming responsible for their actions and inactions. However, social change has influenced the modification of the rite, thus leading to a gradual increase in these societal problems again (Karianjahi, 2008).

The social development of the individual involves, in all societies, a series of well-defined stages, each of which is characterized by its own pattern of obligations, privileges, and types of relationship (Dasen, 2000). It extends into early adulthood and is lately linked to urbanization, industrialization, and formal education. Due to the chaos and unpredictability during adolescence, some cultures or societies have put some measures in place to ensure that the period of adolescence does not become a period of storm and stress and even if it were, it would not be carried on into adulthood. 
Glozah, F. N., \& Lawani, S. (2014). Social change and adolescent rites of passage: A cross cultural perspective. International Journal of Human Sciences, 11(1), 1188-1197. doi: 10.14687/ijhs.v11i1.2909

In preliterate or less developed societies, rites of passage are accepted without equivocation or complaints (Pickering, 1974). As the 'crises' of life are reached, people automatically 'go through' the ritual process. Not to accept the ritual is as unthinkable as a square circle. It is the given way of procedure or life and one that is devoid of alternatives. This is hardly the position in contemporary literate societies such as Norway where adolescents have alternatives as to whether or not to participate in the Russ. Considering the duration of both rites, the Russ lasts for about three weeks whiles the Dipo takes about two weeks to complete. Decades ago, the Dipo lasted for about a year but social change in the form of formal education has made parents unwilling to leave their children in the hands of others for as long as one year. In addition, parents and the society as a whole want to cut down on the expenses associated with the celebration of the rite.

\section{Conclusion}

This paper sought to compare and contrast the Dipo and Russ rites of passage and to examine the role social change and modernity play in these practices. A comparison of Dipo with Russ gives indications of the effect of modern urban civilization on rites and rituals. In non-western societies such as Ghana the ritual is rigid and holistic, changing slowly and often remaining too long to outlive its first usefulness, sometimes retarding change or causing conflict and cultural lag, but reinforcing individual stability.

Although the Dipo and Russ are considered as rites of passages, there are subtle differences between them. One major difference is that with the Dipo adolescents may be banished from the town should they fail to participate and they risk not getting a husband, thereby bringing shame and disgrace to their families. With the Russ, although many people including family and friends encourage an individual to participate, the adolescent can decide not to participate and will not suffer any punishment or penalties. - Families do not experience any form of disgrace or shame. The only form of punishment they might receive comes from their friends and peers in the form of reprobation where, for example, they may not be invited to participate in future get- together parties.

In spite of the major difference between Dipo and Russ they also share some similarities. One major similarity is the procession through town with a special attire to mark the occasion. The adolescents in Dipo put on richly decorated beads, jewelry and expensive velvet or wax print loin cloths and put on earrings for the first time since they went into camping. In the Russ, adolescents put on colourful and magnificent costumes which they spend a lot of time decorating. 
Glozah, F. N., \& Lawani, S. (2014). Social change and adolescent rites of passage: A cross cultural perspective. International Journal of Human Sciences, 11(1), 1188-1197. doi: 10.14687/ijhs.v11i1.2909

In conclusion, rites of passage are very important for a successful transition from adolescence to young adulthood and helps initiates to avoid adopting their own system of initiation that involve risk taking behaviour. Social change and modernity has had both positive and negative influences on the Dipo and Russ rites of passage on Ghana and Norway respectively.

\section{References}

Adjaye, J. K. (1999). Dangerous Crossroads: Liminality and Contested Meaning in Krobo (Ghana) dipo Girls' Initiation. Journal of African Cultural Studies, 12, 5-26. doi: http://dx.doi.org/10.1080/13696819908717837

Beccaria, F., \& Sande, A. (2003). Drinking Games and Rite of Life Projects: A Social Comparison of the Meaning and Functions of Young People's Use of Alcohol during the Rite of Passage to Adulthood in Italy and Norway. Young, 11(2), 99-119. doi: http://dx.doi.org/10.1177/1103308803011002001

Bossard, J. S. H., \& Boll, E. S. (1988). Rite of Passage-A Contemporary Study. Social Forces, 26, 247-255. doi: http://dx.doi.org/10.2307/2572047

Brindis, C., \& Ott, M. (2002). Adolescents, health policy, and the American political process. Journal of Adolescent Health, 30, 9-16. doi: http://dx.doi.org/10.1016/S1054$\underline{139 X(01) 00316-0}$

Corsaro, W. A., \& Johannesen, B. O. (2013). Collective Identity, Intergenerational Relations, and Civic Society: Transition Rituals among Norwegian Russ. Journal of Contemporary Ethnography. doi: http://dx.doi.org/10.1177/0891241613498419

Hall, G. S. (1904). Adolescence: Its psychology and its relation to physiology, anthropology, sociology, sex, crime, religion, and evaluation. New York: Appleton.

Hendry, L. B., \& Kloep, M. (2002). Life-span development: Resources, challenges and risks. London: Thomson Learning.

Hendry, L. B., \& Kloep, M. (2012). Adolescence and Adulthood: Transitions and Transformations. London: Palgrave Macmillan.

Hess, R. S., \& Copeland, E. P. (1997). Stress. In Bear, G. C., Minke, K. M. and Thomas, A. (eds.), Children's Needs II: Development, Problems, and Alternatives. National Association of School Psychologists, Bethesda, MD.

Isaksonl, K. \& Jarvis, P. (1999). The Adjustment of Adolescents during the Transition into High School: A Short-Term Longitudinal Study. Journal of Youth and Adolescence, 28, 1-26. doi: http://dx.doi.org/10.1023/A:1021616407189

Jacquelynne, E., Templeton, J., Barber, B., \& Stone, M. (2003). Adolescence and emerging adulthood: The critical passage ways to adulthood. In Well-being: Positive development across the life course, Marc H. Bornstein, Lucy Davidson, L. M. Corey, and Kristin A. Moore, eds. 383406. Mahwah, N.J.: Lawrence Erlbaum Associates. 
Glozah, F. N., \& Lawani, S. (2014). Social change and adolescent rites of passage: A cross cultural perspective. International Journal of Human Sciences, 11(1), 1188-1197. doi: 10.14687/ijhs.v11i1.2909

Karianjahi, M. (2008). Are Rites of Passage Out of Step? A Kenyan Christian Perspective. Retrieved on 25/01/2014 from http://www.lausanneworldpulse.com/perspectives.php/944?.pg=all

Kloep, M., Güney, F., Çokb, F., \& Simsek, Ö. F. (2009). Motives for risk-taking in adolescence: A cross-cultural study. Journal of Adolescence, 32, 135-151. doi: http://dx.doi.org/10.1016/i.adolescence.2007.10.010

Markstrom, C. A. and Iborra, A. (2003). Adolescent Identity Formation and Rites of Passage: The Navajo Kinaalda'Ceremony for Girls. Journal of Research on Adolescence, 13(4), 399425.doi: http://dx.doi.org/10.1046/j.1532-7795.2003.01304001.x

Merten, D. E. (2005). Transitions and "trouble": Rites of passage for suburban girls. Anthropology and Education Quarterly, 36, 132-148. do: http://dx.doi.org/10.1525/aeq.2005.36.2.132

Ngo, H. M., \& Le, T. N. (2007). Stressful Life Events, Culture, and Violence. Journal of Immigrant Health, 9, 75-84. doi: http://dx.doi.org/10.1007/s10903-006-9018-6

Pickering, W. S. F. (1974). The Persistence of Rites of Passage: Towards an Explanation. The British Journal of Sociology, 25, 63-78. doi: http://dx.doi.org/10.2307/589960

Sande, A. (2002). Intoxication and rite of passage to adulthood in Norway. Contemporary Drug Problems, 29(2), 277-304.

Scheer, S. D., Gavazzi, S. M., \& Blumenkrantz, D. G. (2007). Rites of passage during adolescence. The Forum for Family and Consumer Issues, 12, 2.

Simpson, R. L., \& Simpson, I. H. (1958). The School, the Peer Group, and Adolescent Development. Journal of Educational Sociology, 32, 37-41. doi: http://dx.doi.org/10.2307/2264232

Steegstra M. (2002). 'A mighty Obstacle to the Gospel': Basel Missionaries, Krobo Women and Conflicting Ideas of Gender and Sexuality. Journal of Religion in Africa, 32, 200-230. doi: http://dx.doi.org/10.1163/157006602320292915

Turner, V. (1969). Ritual process: Structure and anti-structure. Hawthorne, NY: Aldine De Gruyter.

Van Gennep, A. (1960). Rites de Passage, English. Chicago: University of Chicago Press. 